\title{
Optimization and economic assessment of renewable energy sources and their combinations for Central Europe
}

\author{
Jan Skovajsa ${ }^{1, *}$ and Martin Zálešák ${ }^{1}$ \\ ${ }^{1}$ Tomas Bata University in Zlin, Faculty of Applied Informatics, Department of Automation and Control Engineering, Nad Stranemi \\ 4511, Zlin, Czech Republic
}

\begin{abstract}
The article deals with the economic evaluation of investment and optimization of the renewable energy sources for family houses. For example, from the point of view of solar systems, the optimal solution is based on the specific application of it. The design is dependent on the location of the panels and ration between active aperture area and real daytime consumption. Common calculations according to actual standards often give overstated results, which also reflected in the value of the investments. The article shows the research of optimal parameters of the thermal solar system for preparing of domestic hot water. A combination of related standards and software TRNSYS are used to find optimal parameters. Thanks to created and verified simulation models, it is possible to design parameters so as to avoid under-dimensioning or over-dimensioning of the each system. Energy price is another factor affects the payback period of investments. This is affected by the used energy sources and their combination. For example, buildings that use electricity to heat water or heating have different energy charges than a building that uses natural gas. So, the aim is to find optimal solution of the combination of renewable energy sources.
\end{abstract}

\section{Introduction}

Nowadays, the emphasis is placed on the use of renewable energy sources for heating, ventilating and air conditioning systems (HVAC). These sources have been massively deployed for many years. However, they are not always designed with respect to the economy of operation and investment. Very often, HVAC systems are designed as independent subsystems, regardless of their possible combinations. This all leads to an efficiency decreasing and investment increasing, in some cases. Therefore, it is advisable to focus on technical and economic optimization at the same time.

The research in this article is focused on systems for the existing family house located in the suburban part of the city of Zlín in the Czech Republic. This object needs to be equipped with a new heat source. The question is which sources with the potential use of renewable energy sources will be the most advantageous. The family house is occupied by a four-member family and calculated heat loss of the object is about $8 \mathrm{~kW}$. Calculations of the economic return and the determination of energy supply prices are based on annual energy for heating, domestic hot water generation and consumption of electrical appliances.

\subsection{Energy requirements}

The first step in choosing energy sources is to determine the energy requirements for the object. Therefore, it is necessary to calculate the heat loss of the building, the power required for a domestic hot water system and also the electricity consumption of electrical appliances. The following subsections describe the calculations and the determination of these parameters.

\subsubsection{Heat load}

For the determination of the annual energy requirement for heating, it is necessary to know the value of the heating degree-days that can be determined by the equation (1). Then the design energy requirement for heating can be determined by the equation (2) [1].

$$
\begin{aligned}
& D D=d\left(\theta_{i s}-\theta_{e S}\right) \\
& Q_{H}=\frac{\varepsilon}{\eta_{o} \eta_{r}} \cdot \frac{24 \cdot Q_{H L} \cdot D}{\theta_{i s}-\theta_{e}}
\end{aligned}
$$

\footnotetext{
where $\varepsilon$ is correction factor of building type and operation [-]

$\eta_{o} \eta_{r}$ regulation and distribution efficiency [-]

$Q_{H L} \quad$ heat loss of the object [kW]
}

\footnotetext{
* Corresponding author: jskovajsa@utb.cz
} 


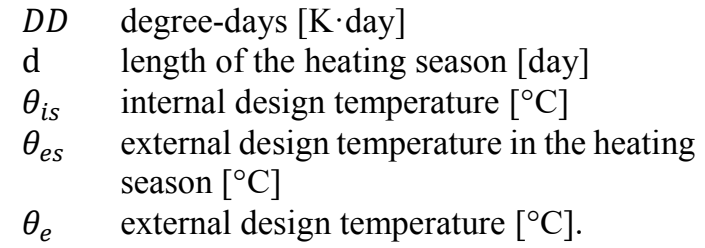

The average internal design temperature is $20{ }^{\circ} \mathrm{C}$, the average external design temperature in the heating season is $4{ }^{\circ} \mathrm{C}$ and the length of the heating season is 226 days. The coefficient $\varepsilon$ was set to 0.75 for the medium object with small heating pause intervals. The regulation and distribution efficiency is set to $95 \%$. Using the equations (1) and (2) we get an annual energy requirement for heating:

$$
Q_{H}=\frac{\varepsilon}{\eta_{o} \eta_{r}} \cdot \frac{24 \cdot Q_{H L} \cdot D}{\theta_{i s}-\theta_{e}}=18 \mathrm{MWh} / \mathrm{y}
$$

\subsubsection{Generation of domestic hot water}

Energy requirement for domestic hot water (DHW) generation can be determined according to CSN 060320 (based on EN 12828+A1 and EN 12831-3) [2,3,5]. However, this does not include solar water systems design. For this purpose, EN 15316-3 and TNI 730302 can be used $[4,6]$. Daily energy requirement can be determined from the equation:

$$
Q_{\text {DHW,d }}=Q_{2 \mathrm{t}}+Q_{2 \mathrm{z}}
$$

Where the theoretical withdrawn heat from the heater, $\mathrm{Q}_{2}$, in $\mathrm{kWh}$, is determined by the relationship (5) and the heat lost during heating and distribution, $\mathrm{Q}_{2 z}$ in $\mathrm{kWh}$, can be determined by the relationship (6):

$$
\begin{gathered}
Q_{2 \mathrm{t}}=c \cdot V_{2 \mathrm{P}}\left(\theta_{2}-\theta_{1}\right) \\
Q_{2 \mathrm{z}}=Q_{2 \mathrm{t}} \cdot \mathrm{z}
\end{gathered}
$$

where $\quad V_{2 \mathrm{P}}$ is DHW requirement in the period $\left[\mathrm{m}^{3}\right]$

c specific heat capacity $\left[\mathrm{kWh} / \mathrm{m}^{3} \mathrm{~K}\right]$

$\mathrm{z} \quad$ energy loss coefficient [-]

$\theta_{1}$ inlet water temperature $\left[{ }^{\circ} \mathrm{C}\right]$

$\theta_{2}$ outlet water temperature $\left[{ }^{\circ} \mathrm{C}\right]$.

The annual energy demand for DHW generation in accordance with standards is obtained by calculating the equations above, and multiplying with the number of days of operation:

$$
Q_{D H W}=365 \cdot(1+z) \frac{\rho \cdot c \cdot V_{2 \mathrm{P}}\left(\theta_{2}-\theta_{1}\right)}{3600}
$$

where $\rho$ is density of water $\left[\mathrm{kg} \cdot \mathrm{m}^{-3}\right]$.

According to standards, the amount of water per person per day is up to 82 litres and energy loss coefficient is up to $50 \%$. This is significant over-dimensioning of the solar DHW system. According to these requirements, the energy required for DHW generation per year would be.

$$
Q_{D H W}=9,4 \mathrm{MWh} / \mathrm{y}
$$

According to experts, the value of the amount of water is too high. It can actually range from 25 to 50 litre per person per day, which also correspond to more realistic values in the standard CSN EN 15361-3. Similarly, energy losses are up to $50 \%$ according to the standard. In real terms, thermal energy losses in DHW distribution and generation are from 20 to $40 \%$. For the building under consideration, the water consumption is set at 45 litres per person per day and the energy loss coefficient is 0.25 . According to these new requirements, the energy required for DHW generation per year is:

$$
Q_{D H W}=4,3 \mathrm{MWh} / \mathrm{y}
$$

The difference of energy is more than $50 \%$ for these examples. This is also reflected in the design of the energy source, eg. the number of solar collectors, the size of DHW tank, parameters of auxiliary heater, etc.

\subsubsection{Total annual energy consumption}

The total energy demand for one year, $\mathrm{Q}_{\mathrm{T}}$, is given by the sum of the annual energy requirements for heating, $\mathrm{Q}_{\mathrm{H}}$, hot water generation, $\mathrm{Q}_{\mathrm{DHW}}$, and energy for household appliances, $\mathrm{Q}_{\mathrm{E}}$, which was set at 4.5 MWh per year.

$$
Q_{\mathrm{T}}=Q_{\mathrm{H}}+Q_{\mathrm{DHW}}+Q_{\mathrm{E}}=26.8 \mathrm{MWh} / \mathrm{y}
$$

All these values are the input parameters for determining the economic returns of selected systems and energy sources. Important point is that different energy sources (natural gas or electricity) have different prices per unit of energy.

\subsection{Electricity supply}

As already mentioned, different systems bring different energy supply conditions and their prices. The price per unit of supplied electricity is given according to the contractual distribution tariff. It is only valid under certain conditions, see current distribution tariffs in the Czech Republic:

- D01d, D02d - normal tarrif for households without electricity production,

- D25d, D26d - electrical storage appliances or electrical water heating,

- D35d - hybrid (mixed) electric heating,

- D45d - household heating using direct electric heating appliances,

- D57d - hybrid or direct electric heating appliances or heat pump system,

- D61d - cottages.

The price of each tariff is composed of the price per energy unit and fees for the circuit breakers, support of renewable energy sources (RES) and the distribution. The fees for breakers, support of RES and distribution are given by the monthly flat rate. It results in a change in the final price per delivered energy unit.

In the case of gas supplies, the issue of the final price is similar. Tariffs are related to the amount of gas taken the less taken gas leads to the higher cost per energy unit. 
The distribution fees are given by the monthly flat rate again.

Each energy source has different final cost per energy. These all differences may cause incorrect investment assessment

\subsection{Economics}

The research also explores the economic return of the proposed systems. Monitored parameters include payback period, discounted payback period, net present value and internal rate of return. These terms are explained and described in the following text.

\subsubsection{Payback period}

Payback period is a very often used economic criterion. It is simple, but not so accurate. It does not consider inflation, discount or lifetime of the project. However, it can be used as a simple indicator of return on investment. Payback period is calculated as:

$$
T_{s}=I N / C F
$$

where $I N$ is investments, costs of the project; $C F \quad$ cash flow, average annual yield.

\subsubsection{Discounted payback period}

The discounted payback period (DPP) formula is used to calculate the length of time to recoup an investment based on the investment's discounted cash flows. By discounting each individual cash flow, the DPP formula takes into consideration the time value of money [7]:

$$
T_{d}=\frac{\ln \left(1+\frac{I N}{C F} \cdot(\alpha-r)\right)}{\ln \frac{(1+\alpha)}{(1+r)}}
$$

where $\alpha$ is inflation (CNB forecast for 2017 is $2 \%$ ); $r \quad$ discount (around 5\%)

\subsubsection{Net present value}

Net present value (NPV) is the difference between the present value of the future cash flows from an investment and the amount of investment. The present value of the expected cash flows is computed by discounting them at the required rate of return [9]:

$$
N P V=C F \frac{(1+r-\alpha)^{t}-1}{(r-\alpha)(1+r-\alpha)^{t}}-I N
$$

where $t$ is project lifetime [year].

Positive net present value means a better return and negative net present value means a worse return than the return from zero net present value. It is one of the discounted cash flow techniques used in the comparative of investment proposals where the flow of income varies over time [8].

\subsubsection{Internal rate of return}

Internal rate of return (IRR) method also takes into account the time value of money. It analyses an investment project by comparing the internal rate of return to the minimum required rate of return. The internal rate of return is the rate at which an investment project promises to generate a return during its useful life. Internal rate of return is the discount rate at which a project's net present value becomes equal to zero [9].

$$
N P V=0 \Rightarrow I R R
$$

If the internal rate of return of the investment project is greater than or equal to the minimum required rate of return, the project is considered acceptable otherwise the project is rejected.

\section{Methods}

This chapter describes an example of optimizing the solar water heating system and choosing suitable energy sources for the family house.

\subsection{Solar water heating system optimizing}

This chapter deals with the practical applications of the mentioned calculations. Part of the chapter is the use of computational methods according to standards and their comparison with the results obtained from dynamic simulations of the same configurations for real climatic conditions. For accurate analysis was made a model of the solar system in the TRNSYS simulation software, see Fig. 1. The simulations used the measured data from the meteorological station located at the FAI TBU in Zlin. These data for climatic conditions were measured in 2017.

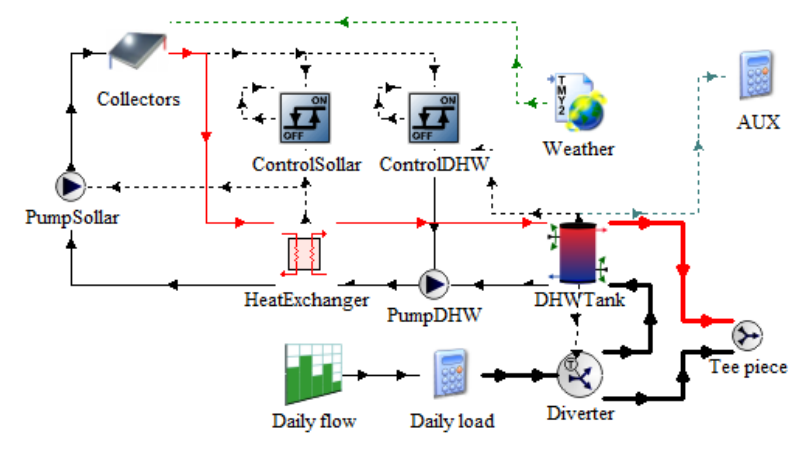

Fig. 1. Simulation model of the solar water heating system.

For calculations and dynamic simulations, the first step is to determine the input parameters for different configurations. The basic parameters of the solar system:

- Number of persons:

4 persons

- DHW consumption: $\quad 351 \cdot \mathrm{p}^{-1} \mathrm{day}^{-1}$ (normal)

$451 \cdot \mathrm{p}^{-1}$ day $^{-1}$ (high)

$821 \cdot \mathrm{p}^{-1} \mathrm{day}^{-1}$ (standard EN)

- inlet/outlet water temp.: $10 / 55^{\circ} \mathrm{C}$

- number of collectors: 1 to $4 \mathrm{pcs}$

- area of the collector: $\quad 2,39 \mathrm{~m}^{2}$

- collector slope/azimuth: 45/0S 
The following table represents the results of the dynamic simulations of the DHW generation for a fourmember family. The simulation take into account the DHW consumption according to the input parameters: Qp,DHw,82, Qp,DHw,45, and Qp,DHw,35. The table and figure below represents the values of average monthly temperatures, $\theta_{e}$, monthly solar gains $\mathrm{H}_{\mathrm{m}}$, and real heat demand Q, based on real data measured in 2017.

Table 1. Monthly solar gains and heat demand for DHW generation.

\begin{tabular}{|c|c|c|c|c|c|}
\hline \multirow{2}{*}{ Month } & $\theta_{\mathrm{e}}$ & $\mathrm{H}_{\mathrm{m}}$ & $\mathrm{Q}_{\mathrm{p}, \text { DHW,35 }}$ & $\mathrm{Q}_{\mathrm{p}, \text { DHW, } 45}$ & $\mathrm{Q}_{\mathrm{p}, \text { DHW }, 82}$ \\
\cline { 2 - 6 } & ${ }^{\circ} \mathrm{C}$ & $\mathrm{kWh} / \mathrm{m}^{2}$ & $\mathrm{kWh}$ & $\mathrm{kWh}$ & $\mathrm{kWh}$ \\
\hline JAN & $-5,5$ & 59,3 & 227 & 293 & 536 \\
\hline FEB & 1,5 & 59,4 & 203 & 265 & 485 \\
\hline MAR & 7,5 & 114,7 & 222 & 288 & 536 \\
\hline APR & 8,5 & 110,9 & 213 & 280 & 519 \\
\hline MAY & 15,2 & 132,0 & 220 & 289 & 537 \\
\hline JUN & 20,4 & 132,2 & 211 & 281 & 519 \\
\hline JUL & 21,3 & 123,2 & 225 & 291 & 537 \\
\hline AUG & 13,9 & 140,2 & 211 & 286 & 537 \\
\hline SEP & 10,3 & 97,6 & 213 & 281 & 519 \\
\hline OCT & 4,8 & 83,4 & 223 & 292 & 537 \\
\hline NOV & 1,5 & 44,4 & 220 & 285 & 519 \\
\hline DEC & 10,0 & 27,9 & 229 & 294 & 537 \\
\hline \multicolumn{2}{|c|}{ SUM } & $\mathbf{1 1 2 5}$ & $\mathbf{2 6 1 7}$ & $\mathbf{3 4 2 5}$ & $\mathbf{6 3 1 8}$ \\
\hline
\end{tabular}

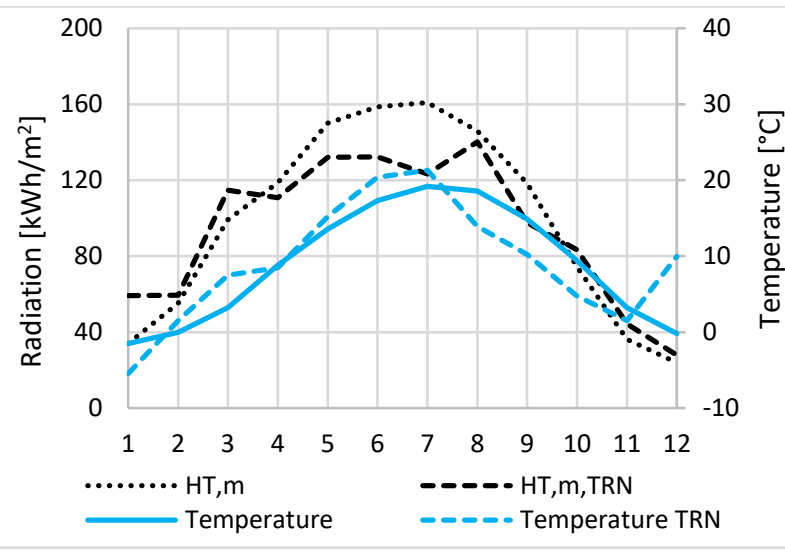

Fig. 2. Average monthly solar gains and temperature.

Based on the data obtained so far, it is possible to start solving the optimization of the proposed solar water heating system. The optimization is based on the search for the optimal number of solar collectors for the different DHW consumption. From a technical point of view, the optimal system can cover as much heat demand as possible and it can use the maximum installed capacity at the same time. It means the system works with the minimum of energy surplus. From an economic point of view, this situation is also appropriate, as there is a positive ratio of investment and energy savings.

The following tables show the results of the simulations for a different number of solar collectors and different DHW consumption. It is possible to see the total heat demand to be covered, QDHw, the theoretically usable heat gains of the solar collectors, $\mathrm{Q}_{\mathrm{k}, \mathrm{u}}$, and the real utilization of the solar system, $\mathrm{Q}_{\mathrm{ss}, \mathrm{u}}$. The table also contains the percentage utilization of solar radiation, $\mathrm{n}_{\mathrm{sol}}$, and installed power of solar collectors, $\mathrm{n}_{\text {sc }}$. The percentage utilization of installed power is the ration of the heat real used and the theoretically achievable maximum.

Table 2. Thermal gains and system utilization over the year.

\begin{tabular}{|c|c|c|c|c|c|}
\hline \multirow{2}{*}{ Pcs/cons } & $\mathrm{Q}_{\mathrm{p}, \mathrm{DHW}}$ & $\mathrm{Q}_{\mathrm{k}, \mathrm{u}}$ & $\mathrm{Q}_{\mathrm{ss}, \mathrm{u}}$ & $\mathrm{n}_{\text {sol }}$ & $\mathrm{n}_{\mathrm{sc}}$ \\
\cline { 2 - 6 } & $\mathrm{kWh} / \mathrm{m}^{2}$ & $\mathrm{kWh} / \mathrm{y}$ & $\mathrm{kWh} / \mathrm{y}$ & $\%$ & $\%$ \\
\hline $1 / 35$ & 2617 & 1374 & 1374 & 53 & 100 \\
\hline $1 / 45$ & 3425 & 1409 & 1409 & 41 & 100 \\
\hline $1 / 82$ & 6318 & 1487 & 1487 & 24 & 100 \\
\hline $2 / 35$ & 2617 & 2714 & 2186 & 84 & 81 \\
\hline $2 / 45$ & 3425 & 2807 & 2650 & 77 & 94 \\
\hline $2 / 82$ & 6318 & 3006 & 3006 & 48 & 100 \\
\hline $3 / 35$ & 2617 & 3741 & 2415 & 92 & 65 \\
\hline $3 / 45$ & 3425 & 3905 & 3988 & 87 & 77 \\
\hline $3 / 82$ & 6318 & 4305 & 4298 & 68 & 100 \\
\hline $4 / 35$ & 2617 & 4660 & 2501 & 76 & 54 \\
\hline $4 / 45$ & 3425 & 4852 & 3177 & 76 & 65 \\
\hline $4 / 82$ & 6318 & 4852 & 4782 & 76 & 99 \\
\hline
\end{tabular}

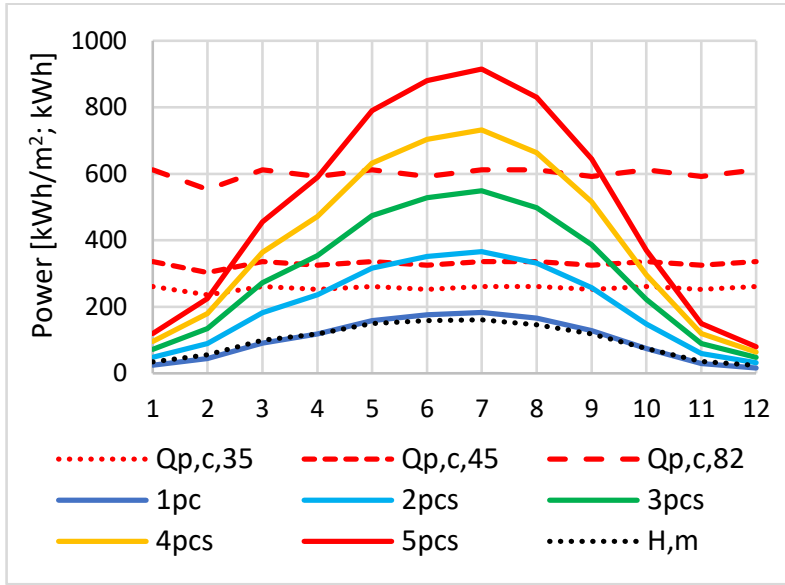

Fig. 3. Heat demands and maximum solar gains over the year.

From the tables and graph above, it is clear that one piece of collector covers from 24 to $53 \%$ of the heat demand and its power is utilized at $100 \%$. This shows that the system is under-dimensioned and unable to cover the heat demand in any period. For two and three pieces, the situation is more positive. The coverage of the heat demand is from 48 to $84 \%$ and the power utilization is 81 to $100 \%$. For more collectors, the coverage of the heat demand is further increased, but the percentage utilization of the installed power decreases, see Tab. 2. It means the system is over-dimensioned. As can be seen, the difference between one and two pieces of solar collectors is considerable. However, adding more pieces does not provide adequate additional energy coverage. It only leads to increasing investments with decreasing usability. Among other things, over-dimensioning of the system leads to stagnation and thus to degradation of the heat transfer medium and solar collectors [10-13]. The system with two or three solar collectors appears to be optimal for the designed conditions. 
The next charts show the results for higher DHW consumption - $451 \cdot \mathrm{p}^{-1} \mathrm{day}^{-1}$. This option can cover almost any situation in a normal household, so it is chosen as the default. In the charts, it can be seen that two pieces of solar collectors almost ideally cover the heat demand in the months of April to September. This option has optimal use of installed power with only small surpluses.

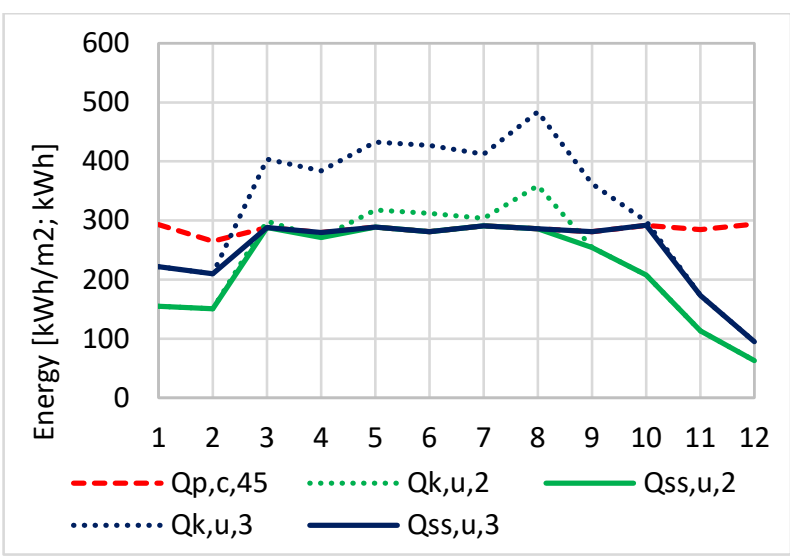

Fig. 4. Two and three pieces, consumption $451 \cdot \mathrm{p}^{-1} \mathrm{day}^{-1}$.

From the obtained data and information, it is possible to move on to the economic evaluation of investments of individual variants of the solar water heating system.

The same procedure was used to determine the optimal parameters of other energy sources for which the economic assessment is carried out in the next chapter.

\subsection{Energy sources}

This chapter is related to examples of family houses using natural gas (Case 1) and electricity (Case 2) as a primary energy source. The results show differences in suitable choice of energy sources for these cases. In both cases, several possible options are chosen. Every option includes changes in energy prices, regular service, checks, and possible power overlays that may lead to an increase in the payback period of individual investments.

For the investment assessment, the data are determined according to CNB's website (Czech National Bank) [14]: exchange rate $1 \mathrm{EUR}=25.5 \mathrm{CZK}$, inflation 2 $\%$ and discount rate $0.5 \%$. The lifetime of the projects is 20 years. The prices of energies are based on current price lists of distributors in the Czech Republic in 2018. Every investment is based on independent supply and demand of individual technical solution.

The following list presents the possible solutions and their combinations:
A: Default
B: New condensing boiler (CB)
C: $\quad$ New electric boiler (EB)
D: Heat pump (HP)
E: Solar water heating $(\mathrm{SWH})$
F: $\quad$ SWH and condensing boiler $(\mathrm{SWH}+\mathrm{CB})$
G: $\quad$ SWH and electric boiler (SWH+EB)
$\mathrm{H}: \quad$ SWH and heat pump (SWH+HP)
I: $\quad$ Photovoltaics (PV)
$\mathrm{J}$ : $\quad \mathrm{PV}$ and condensing boiler $(\mathrm{PV}+\mathrm{CB})$
K: $\quad$ PV and electric boiler (PV+EB)
$\mathrm{L}: \quad \mathrm{PV}$ and heat pump (PV+HP)
$\mathrm{M}: \quad \mathrm{PV}$ and solar water heating $(\mathrm{PV}+\mathrm{SWH})$
$\mathrm{N}: \quad \mathrm{PV}+\mathrm{SWH}$ and cond. boiler $(\mathrm{PV}+\mathrm{SWH}+\mathrm{CB})$
$\mathrm{O}: \quad \mathrm{PV}+\mathrm{SWH}$ and electric boiler $(\mathrm{PV}+\mathrm{SWH}+\mathrm{EB})$
$\mathrm{P}: \quad \mathrm{PV}+\mathrm{SWH}$ and heat pump $(\mathrm{PV}+\mathrm{SWH}+\mathrm{HP})$

In case of combinations of different sources (gas, electricity, RES), the issue of energy price changes and their power co-operation needs to be addressed.

\section{Results and discussion}

Based on collected data and selected energy sources, investment assessment can be performed. The assessment is done for individual energy sources and also for their mutual combinations, see the previous chapter. As already mentioned, simulations and calculations deal with two possible cases - the reconstruction of a family house using natural gas or electricity as a primary energy source.

\section{Case 1: Family house using an old gas boiler}

In this case, it is a system with the old gas boiler which can be replaced by a new condensing boiler or an electric boiler with a possible combination of RES. Variants B, C, $\mathrm{D}, \mathrm{E}$ and I are only an extension of the existing system. The table below contains possible solutions, see chapter 2.2. It is possible to see their Investment (IN) and Cash Flow (CF). CF takes into account the change in energy prices and the simultaneous running of more technologies as well as the real profit of energy from RES. The table also includes a Discounted Payback Period (DPP), Net Present Value (NPV), and Internal Rate of Return (IRR). From these values, it can be seen whether the investment pays off or not.

Table 3. Economic assessment of energy sources for a family house using a gas boiler.

\begin{tabular}{|c|r|r|r|r|r|}
\hline Var. & $\begin{array}{c}\text { IN } \\
\text { [EUR] }\end{array}$ & $\begin{array}{c}\text { CF } \\
\text { [EUR] }\end{array}$ & $\begin{array}{c}\text { DPP } \\
\text { [YEAR] }\end{array}$ & $\begin{array}{c}\text { NPV } \\
\text { [EUR] }\end{array}$ & $\begin{array}{c}\text { IRR } \\
{[\%]}\end{array}$ \\
\hline A & - & - & - & - & - \\
\hline B & 1804 & 245 & 7.1 & 3959 & 14.2 \\
\hline C & 1196 & -70 & - & -2835 & - \\
\hline D & 7176 & 900 & 7.6 & 14000 & 13.0 \\
\hline E & 1529 & 102 & 13.7 & 869 & 4.9 \\
\hline F & 3333 & 255 & 12.1 & 2667 & 6.4 \\
\hline G & 2725 & 75 & 29.5 & -970 & - \\
\hline H & 8235 & 1136 & 6.9 & 18487 & 14.5 \\
\hline I & 3765 & 358 & 9.9 & 4657 & 9.1 \\
\hline J & 5569 & 603 & 8.7 & 8616 & 10.8 \\
\hline K & 4961 & 94 & 39.2 & -2742 & - \\
\hline L & 10941 & 1089 & 9.4 & 14691 & 9.7 \\
\hline M & 5294 & 460 & 10.7 & 5526 & 8.0 \\
\hline N & 7098 & 613 & 10.8 & 7324 & 7.9 \\
\hline O & 6490 & 264 & 21.5 & -279 & - \\
\hline P & 12000 & 1325 & 8.6 & 19179 & 11.1 \\
\hline
\end{tabular}

As can be seen from the table, in the case of changing to a fully electric system it is possible to obtain the 
distribution tariff for electric heating. It leads to a reduction of electricity prices, but the total energy costs are higher than at the current state. The interesting finding is about solar collectors, which have a large annual profit, but their DPP is very long, because of the gas price. On the other hand, this situation is different with using the heat pump or photovoltaic system.

In this case, it seems to be the best option is to install the heat pump or its combined with solar collectors or photovoltaics.

\section{Case 2: Family house using an electric boiler}

In the case of a family house using an electric heating, condensing gas boiler combined with RES is the best option in terms of the payback period. However, it is envisaged to set up a gas connection in the price of about 1200 EUR. It can be much more, or it can be unrealizable in reality. If the realization of gas connection is problematic, the HP and its combination with other RES is the most advantageous option.

Table 4. Economic assessment of energy sources for a family house using an electric boiler.

\begin{tabular}{|c|r|r|r|r|r|}
\hline Var. & $\begin{array}{c}\text { IN } \\
\text { [EUR] }\end{array}$ & $\begin{array}{c}\text { CF } \\
\text { [EUR] }\end{array}$ & $\begin{array}{c}\text { DPP } \\
\text { [YEAR] }\end{array}$ & $\begin{array}{c}\text { NPV } \\
\text { [EUR] }\end{array}$ & $\begin{array}{r}\text { IRR } \\
{[\%]}\end{array}$ \\
\hline $\mathrm{A}$ & - & - & - & - & - \\
\hline $\mathrm{B}$ & 2980 & 315 & 9.0 & 4421 & 10.5 \\
\hline $\mathrm{C}$ & 1196 & 58 & 18.1 & 178 & 1.8 \\
\hline $\mathrm{D}$ & 7176 & 1129 & 6.2 & 19398 & 16.7 \\
\hline $\mathrm{E}$ & 1529 & 157 & 9.2 & 2175 & 10.1 \\
\hline $\mathrm{F}$ & 4510 & 333 & 12.5 & 3320 & 6.0 \\
\hline $\mathrm{G}$ & 2725 & 216 & 11.7 & 2358 & 6.9 \\
\hline $\mathrm{H}$ & 8235 & 1205 & 6.6 & 20126 & 15.5 \\
\hline $\mathrm{I}$ & 3765 & 207 & 16.3 & 1113 & 2.9 \\
\hline $\mathrm{J}$ & 6745 & 730 & 8.7 & 10442 & 10.8 \\
\hline $\mathrm{K}$ & 4961 & 280 & 15.9 & 1625 & 3.2 \\
\hline $\mathrm{L}$ & 10941 & 1351 & 7.7 & 20844 & 12.7 \\
\hline $\mathrm{M}$ & 5294 & 379 & 12.8 & 3622 & 5.7 \\
\hline $\mathrm{N}$ & 8275 & 749 & 10.4 & 9342 & 8.5 \\
\hline $\mathrm{O}$ & 6490 & 438 & 13.6 & 2805 & 5.0 \\
\hline $\mathrm{P}$ & 12000 & 1427 & 8.0 & 21573 & 12.2 \\
\hline
\end{tabular}

Compared to the first case there is a change in solar collectors, their payback period was very long in the first variant, but they can be successfully applied here, especially in combination with the HP. The opposite change is photovoltaic, which almost does not worth it. It does not bring significant energy savings or reduced energy unit prices in this case. An interesting thing is the combination of the HP and PV, which has a very interesting net present value of the project.

\section{Comparison of individual solutions}

The most obvious presentation of the results of each solution can be seen in the graphs below (Figure 5, Figure 6 , Figure 7) that include discounted payback period, net present value and internal rate of return.

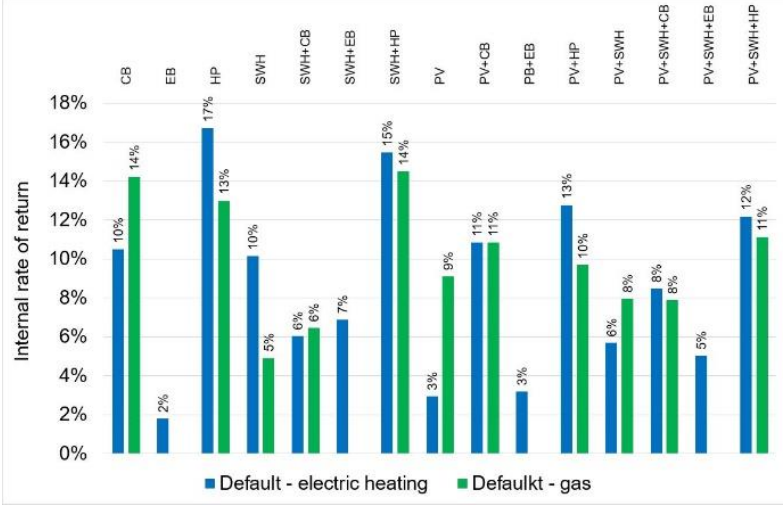

Fig. 5. Discounted payback period.

The replacement of gas boiler by an electric boiler is not shown in the charts because this option has negative cash flow.

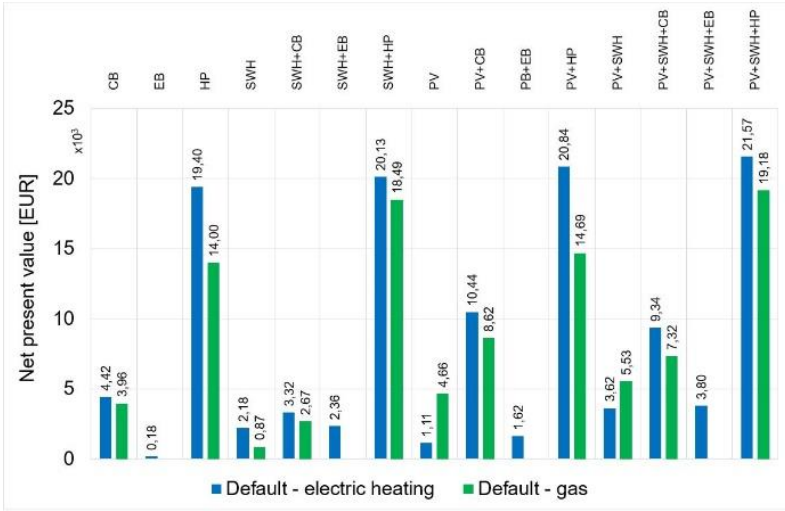

Fig. 6. Net present value.

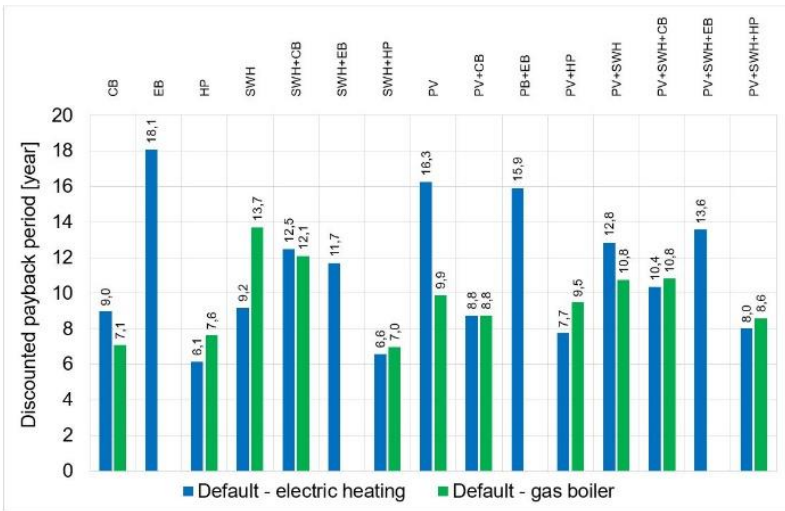

Fig. 7. Internal Rate of Return.

\section{Conclusion}

Nowadays, many buildings are under construction or reconstruction, and the old heat sources are replacing by new. There is an emphasis on using renewable energy sources. It may seem that the selection is clear, and the investment in the different systems will return very quickly. However, in reality, the choice of a suitable energy source for heating and hot water generation is not entirely straightforward and unambiguous. Two cases of the real family house were described in the text. The article shows different options for investing in a new energy source. From the results, the heat pump is advantageous for all possible cases. The use of solar 
collectors and photovoltaic panels may be contra productive. On the other hand, their application may be very advantageous, in some cases, especially in combination with other sources. The article shows how important it is to take into account the combination of different sources and their mutual influence.

This work was supported by the Ministry of Education, Youth and Sports of the Czech Republic within the National Sustainability Programme project No. LO1303 (MSMT7778/2014) and also by the European Regional Development Fund under the project CEBIA-Tech No. CZ.1.05/2.1.00/03.0089 and also by the Internal Grant Agency of Tomas Bata University under the project No. IGA/CebiaTech/2019/001

\section{References}

1. EN 12831-1:2018. Brussel: CEN (2018)

2. CSN 06 0320. Praha: UNMZ - Czech Office For Standards, Metrology and Testing (2006)

3. EN 12828:2012+A1:2014. Brussel: CEN (2014)

4. EN 15316-3:2017. Brussel: CEN (2017)

5. EN 12831-3:2018. Brussel: CEN (2018)

6. TNI 73 0302. Praha: UNMZ - Czech Office For Standards, Metrology and Testing (2014)

7. Finance Formulas: Discounted Payback Period (DPP), (2018)

8. Business Dictionary: Net present value (NPV). WebFinance, Austin (2018)

9. Accounting for management: Internal rate of return method, (2017)

10. P. V. Quiles, F. J. Aguilar, S. Aledo. Enrgy Proced, 48, 172 - 180 (2014)

11. Z. Xinyu, Y. Shijun, X. Wei, Z. Xuejing, H. Tao, H. Zhulian, Z. Lei, D. Yu. Enrgy Proced, 30, $824-828$ (2012)

12. J. C. Fernandes, A. Nunes, M. J. Carvalho, T. C. Diamantino. Sol Enrgy Mat Sol C, 160, 149 - 163 (2017)

13. X. Wang, L. Jiang, M. Du, L. Hao, X. Liu, Q. Yu. Enrgy Proced, 49, 1747 - 1755 (2014)

14. Czech National Bank, Available: www.cnb.cz/en/, (2018) 